\title{
Style Equivalence in Prose Translation: Citing Zhang Peiji's Translation of Bing Xin's Prose
}

\author{
Yang Yang \\ Department of Translation and Interpreting, Chengdu Institute Sichuan International Studies University, Chengdu, China \\ Email: YY_805@163.com
}

How to cite this paper: Yang, Y. (2021) Style Equivalence in Prose Translation: Citing Zhang Peiji's Translation of Bing Xin's Prose. Open Access Library Journal, 8: e7740.

https://doi.org/10.4236/oalib.1107740

Received: July 8, 2021

Accepted: August 2, 2021

Published: August 5, 2021

Copyright $\odot 2021$ by author(s) and Open Access Library Inc.

This work is licensed under the Creative

Commons Attribution International

License (CC BY 4.0).

http://creativecommons.org/licenses/by/4.0/

(c) (i) Open Access

\begin{abstract}
Prose, characterized by its style, is different from other types of literature. As an important part of literature, prose plays an important role in cultural communication; thus, the analysis of prose translation is very important. This paper makes a tentative approach in the following text to analyze how to realize style equivalence through markers of style, specifically "form markers", proposed by Professor Liu Miqing, including lexical markers, markers of figures of speech and textual markers under the guidance of Nida's functional theory, by using Zhang Peiji's translation of Bing Xin's prose as examples.
\end{abstract}

\section{Subject Areas}

Linguistics, Literature

\section{Keywords}

Prose Translation, Style, Functional Equivalence, Form Markers

\section{Introduction}

Prose, a literary genre enjoying a similar status as novel, poem and drama, plays an important role in literature field. Unlike novel and drama, which is more about the content, prose and its style are inseparable. Thus, a very important objective of prose translation is to achieve stylistic equivalence, so the target readers would be able to resonate with the author just as the readers of the source language did.

In recent years, there is a growing attention to the translation of prose and many believe that style is translatable even though not easy. However, compared with novel, the attention to style is much less. On CNKI, the author finds 287 papers related to the search words "novel's style translation", while only 134 re- 
lated to "prose's style translation". Among those papers, key words such as style reproduction, functional equivalence, Zhang Peiji's translation, and aesthetic theory appear most frequently. Stylistic markers theory is found only in three papers. Zhang Liming [1] applies corpus tool and does a case study of the translation of the prose First Snow written by John Boynton Priestley in terms of the stylistic markers with reference to functional theory. Huang Lihua and Wang Jianfang [2] use "non-form markers" of Liu Miqing's theory to analyse style reproduction in Zhang Peiji's translation. Yang Jie [3] uses "non-form markers" and "non-form markers" to analyse Liu Bingshan's translation of the Roast Pig by English essayist Charles Lamb. All these have shown that scholars start to apply functional theory and Liu Miqing's stylistic markers theory on style translation. Previous studies either use only one of the above two theories or apply it to English prose only. In the following text, the author attempts to combine both theories and applies them in the translation of Chinese prose and believes this is useful for promoting and spreading of Chinese culture.

Bing Xin is a famous prose writer during the enlightenment period of China in the early period of the twentieth century. Her prose is renowned for being succinct, elegant and exquisite. It is written in a fluent and natural manner, imbibing both the classical style as well as a modern spirit. Her writing rose to prominence as early as 1919, known as the "Bing Xin's Style". Some of her works include A Maze of Stars (Fan Xing) and Little Orange Lamp (Xiao Judeng), which are poem and prose collection respectively. Even in the $21^{\text {st }}$ century, her writing still enjoys wide popularity.

In Selected Modern Chinese Prose Writing, Zhang Peiji, a famous translator, makes a successful attempt in translating Bing Xin's prose into English while trying to retain its original style. This paper is going to study the Zhang Peiji translated version by using the "form markers" of Liu Miqing's stylistic markers theory under the guidance of Nida's functional equivalence.

\section{Criteria for Stylistic Equivalence in Prose Translation}

Translation of prose is not just the expression of literal meaning, but also communication of its style, which can be done only when the translators fully grasp its meaning, author's intention, hidden message, and etc. Usually prose is imbued with many cultural connotations and images, related to history, regions, and customs, just to name a few. Therefore, prose translation is a creative work, the translator should try to uncover and convey the hidden messages expressed through its stylistic elements on the basis of faithful translation.

\subsection{Nida's Theory-Functional Equivalence}

In accordance with the characteristics of prose translation, Nida's theory offers us a standard. He holds that translation is to recreate the meaning and style of the original text, and to realize "the closest natural equivalent", namely, the translation should be faithful in its messages and consistent in its style, and 
without translationese, rather than striving for "identity" in the target language. He further puts forward the famous theory "functional equivalence", which is defined in terms of the degree to which the receptors of the message in the receptor language respond to it in substantially the same manner as the receptors in the source language. "Translating consists in reproducing in the receptor language the closest natural equivalent of the source-language message, in terms of meaning and style. The readers of a translated text should be able to comprehend it to the point that they can conceive if how the original readers of the text must have understood and appreciate it" [4]. He illustrates his view with the example "white as snow" from a passage in the Bible. He holds that translation should be rendered in a way so that the receptors would be able to have similar response as the writer. If the receptors do not know snow, or if they do not have a word for it? In these two cases, the translation may explain the phenomenon by using a metaphor, or finding equivalent idioms, e.g. "white as egret feathers". The key here is to express the meaning, while the word "snow" is not indispensable to the message.

In this way, Nida shifts the focus from the author to the readers and their reaction through functional equivalence. He emphasizes the importance of both content and style. His theory breaks away from traditional criteria and opens a new sphere for translators, providing a theoretical orientation to translators dealing with the difficulties arising from translation.

\subsection{Liu Miqing's Style of Translation and Adaptation}

Liu Miqing emphasizes style in translation. In his book Stylistics and Translation, he raises the theory "Style of Translation" and he holds that style reproduction is the pinnacle of translation skill.

"The quality of translation is measured by high adaptation of the translated version, and reproduction of canon's style and spirit. What's more, this is the best proof for a translator's skills and excellence" [5]. He suggests translators to start from the following aspects: firstly, translation should adapt to the original stylistics as much as possible; secondly, the level of formality should be taken into consideration, so the translation could adapt to the author's style.

Professor Liu Miqing holds that since style is neither illusory nor visionary but should be reflected by concrete and specific standard, which he called "markers of style". He divides the markers of style into two categories, form and non-form markers. Prof. Liu classifies the "form markers" into six types in accordance with linguistic rules: phonological markers, register markers, syntactic markers, lexical markers, markers of figures of speech and textual markers. " Non-form markers' refer to those stylistic features that are usually judged by readers' aesthetic feeling towards literature, while 'form markers' refer to the language's formal features which serve to mark the style of the source language" [6]. With careful analysis of those respective forms, we can identify the source language's "form markers" and its style. 


\section{Stylistic Equivalence in Prose Translation}

The understanding and translation of style involves two main processes-understanding of the source language and appropriate presentation in the target language. During the process of translation, the translator has to use message interpretation as a bridge, and shifts between analysis and reorganization of the message. It is also necessary for him or her to rearrange message according to different context. In the following text, this paper will use the "form markers" proposed by Prof. Liu, including "syntactic markers", "lexical markers”, “markers of figures of speech" and "textual markers" to analyse how Zhang's translation achieve stylistic equivalence in translation.

\subsection{Lexical Markers}

The lexical markers are often interpreted as "idiolect", indicating the writer's personal tendency to choose lexis (words). In comparison to register markers, which to some extent, shows the social relationship, the lexical markers mainly involve the personal tendency. For instance, some writers like to use some simple and plain words, some may prefer elegant and archaic words, and others like to make his works vivid and humorous by using many colloquial words. Therefore, the identification of the lexical markers is vital for understanding a writer's peculiar style in his works.

With a combination of literary and colloquial language, Bing Xin's prose is an object of appreciation to the readers. When translating it into English, it is very important to note that the language should meet the contextual need as well as style need. Professor Zhang's translation retains her characteristics like succinctness, vividness and lyric. Thus, reading the translated text is also an enlightening and enjoyable experience.

\subsubsection{Literary Language}

1) 特别是灯节, 那时我们家住在南后街, 那里是灯市的街, 元宵前后,

“花市灯如昼” , 灯影下人流潮涌, 那光明绚丽的情景就说不尽了。(来

自《我的父母之乡》, 冰心, 1982)

Particular mention, however, should be made of the Lantern Festival when Nanhoujie, the street known for its lantern fair and also the street where we lived, became as bright as broad daylight at night with myriads of lanterns and streams of spectators. The splendor and magnificence of the scene is beyond all description. (from The Land of My Ancestors, by Bingxin, 1982)

The sentence “花市灯如昼 (Huashi deng ru zhou)” (its lantern fair...with myriads of lanterns and streams of spectators) is quoted from the poem "Lantern Festival, to the tune of Sheng-cha-zi” (生查子・元夕 (Sheng cha zi yuanxi)), written by Ouyang Xiu, a famous Chinese poet in Song dynasty. In this poem, he wrote “去年元夜时，花市灯如昼(qu nian yuan ye shi, hua shi deng ru zhou)” (In the Lantern Festival last year, lanterns were bright as if by day in the flower market) (by anonymous translator from internet), depicting a lively scene of the 
flower market, which was lighted up by the lanterns on the lantern fair. In this sentence with five characters, the poet managed to describe a beautiful scenery with succinct language, by using a simple word “昼” (Zhou) rather than “白天” (Bai-tian) to describe "day time". In response to that, Zhang used a idiom "broad daylight" in translation, making it concise but still poetic. The idiom "broad daylight" means "during the day when people and things can be easily seen rather than at night" [7].

In the next sentence “灯影下人流潮涌(Deng ying xia ren liu chao yong)” (...with myriads of lanterns and streams of spectators), Bing Xin used “灯影 (Deng ying)" (shadow of lanterns) a brief yet comparable phrases to describe the ocean of lanterns. The translation "shadow of lanterns" has a poetic touch and is very often seen in Chinese poems, such as “见说平时灯影里, 玄宗潜伴太真游 (Jian shuo ping shi deng ying li, Xuanzong qian ban Taizhen you)" (As rumor goes, Emperor Xuanzong of Tang Dynasty would dress in plain clothes and travel with his favorite concubine Taizhen on these days amidst the shadow of lanterns) by poet Yuan Zhen. Zhang used “myriads of lanterns” for “灯影(Deng ying)", instead of "thousands of lanterns", which is more close to the context, as "myriads" is a literary word.

2) 父母亲和他们的兄弟妯娌都有许多别情要叙。(来自《祖父和灯火管 制》，冰心，1982）

For it was but natural that after the long separation, my parents enjoyed hearty chats about the old days with their brothers and in-laws. (From Grandpa and Nightly Blackout, Bing Xin, 1982)

One of "Bing Xin Style's" characteristics is the combination of literary and colloquial words and expressions in writing in a fluent and natural way. The phrases “别情(bie qing)” and “要叙(yao xu)” are representative examples. “别情 (bie qing)" means "the feelings arise from long parting”. In the phrase “要叙 (yao $\mathrm{xu})$ ”, “叙(xu)" means "talk about matters related to each other". It is a simple word, with subtle meaning. Chinese is paratactic, so it is acceptable that “别 (bie)” (parting) and “情(qing)” (feelings) are grouped together as one phrase. However, English is hypotactic. If the hidden logic between these two words are not conveyed, it would puzzle the readers. In the translated version, Zhang separated these two words and revealed their hidden logic by the phrase "long separation" and "hearty chats". As it was hometown visit after long parting, Zhang added "the old days".

\subsubsection{Images}

Images are important elements in Chinese writing, especially in prose and poetry. Chinese poets and writers like to describe the natural phenomenon or the behavior of birds or animals and express their feelings or attitudes through metaphor or images. Bing Xin's prose is permeated with vivid images and bright colors.

3) 驴脚下的泥, ……田沟里的水, ……近村的绿树, 都笼在湿烟里。

(来自《笑》，冰心，1920） 
The ground under my donkey's feet was slippery with mud. The water in the field ditches was murmuring. The green trees in the neighboring village were shrouded in a mist. (From Smile, Bing Xin, 1920)

These sentences are taken from the prose "Smile", written in the earlier life of Bing Xin. She was only in her 20s. In these sentences, she uses many simple images, like “驴脚(lú jiao)”(donkey feet), “泥(ni)” (mud), “水(shui)” (water), “绿 树(lü shu)” (green trees), and “湿烟(shi yan)” (misty), to piece together a joyful countryside image. Zhang applied literal translation and faithfully translated all these images in target languages as "donkey's feet", "mud", "water", "green trees" and "mist".

4) 从严冷枯黄的北方归来, 看到展现在我眼前的青山碧水, 红花绿叶, 使我惊讶而欢喜! (来自《我的父母之乡》, 冰心, 1982)

Returned from the bitter cold North with its drab and dried up vegetation, I was amazed and delighted when greeted by the charming scenery of sapphire mountains and emerald rivers as well as red flowers and green leaves.

(from The Land of My Ancestors, by Bingxin, 1982)

In this example, it can be seen Bing Xin was skillful in diction and coinage. In this sentence, several expressions of four-character structure are used to describe the scenery, including “严冷枯黄(yan leng ku huang)”, “青山碧水(qing shan bi shui)” and “红花绿叶(hong hua lü ye)". It is important to note not all of them are standard idioms with four-character structure. For instance, “严冷枯黄(yan leng ku huang)" is a recombination and restructuring of “严寒(yan han)" (severe cold) and “枯黄(ku huang)” (withered and yellow). In Chinese, “枯黄(ku huang)” already has the implied meaning of leafless and lifeless autumn or winter. Yet, that is not the case in English. Therefore, Zhang used addition method, by using concrete objects to follow these adjectives, “drab and dried up vegetation”. “青山碧水(qing shan bi shui)" means "green mountains, and jade-green rivers". It is more commonly known as “青山绿水(qing shan lü shui)” (green mountains rivers). To convey the intention of Bing Xin, Zhang used more accurate "sapphire" and "emerald", instead of "green" color, adding aesthetic beauty to the sentence.

\subsection{Syntactic Markers}

Style is the marker of a writer's mind, and syntactic structure is a major component of style. Syntactic markers refer to different sentence patterns that arrange the words into different orders. When some sentence patterns (i.e. coordination, subordination, parallel, antithesis, omission, and so on) are alternately used in one context or text, the syntactic markers indicating the style will be easily identified. For example, Hemingway likes simple and forceful sentence, while Faulkner prefers complex subordination patterns.

Bing Xin's prose is predominantly characterized by simple and succinct sentences. It is crucial for the translator to retain the author's syntactic pattern, yet doing no damage to the meaning. 


\subsubsection{Sentence Restructuring}

In Chinese, we are inclined to write long and redundant sentences, and combine all the information into one sentence. It is important to analyze and reorganize them, so they are understandable by English readers. Division and combination are the most commonly employed translation methods. They play a significant role in achieving Subject-Verb consistence and logic coherence. Division and combination are usually applied in one compound sentence.

5) 我们这所大房子里也安上了电灯, 这在福州也是一件新鲜事, 我们这 班孩子跟着安装的工人们满房子跑, 非常地兴奋欢喜! (来自《祖父和灯 火管制》，冰心，1982)

..., Fuzhou began to have its own power company and electric lights were to be installed in our big house too. That was something new in our home town. We kids, wild with excitement and joy, ran here and there in the house at the heels of the electricians. (From Grandpa and Nightly Blackout, Bing Xin, 1982)

In Chinese language, it is normal practice to change or switch subjects within one sentence, however, it is not acceptable grammatically in English language. Therefore, “这在福州也是一件新鲜事(zhe zai fuzhou ye shi yi jian xin xian shi)" (That was something new in our home town) is treated as a separate sentence in translation, because its subject does not agree with the sentences before and after. “非常地兴奋欢喜(fei chang di xing fen huan xi)” (wild with excitement and joy) is originally positioned at the end of this long sentence. To avoid misunderstanding, it is placed right after its antecedent “我们这班孩子(wo men zhe ban hai zhi)" (we kids).

6) 我在故乡走的地方不多, 但古迹、侨乡, 到处可见, 福建华侨, 遍于 天下。(来自《我的父母之乡》, 冰心, 1982)

I did not visit all the local attractions in Fuzhou. Everywhere we could find historical relics as well as villages and towns inhabited by relatives of overseas Chinese. Fujianese expatriates are found all over the world. (from The Land of My Ancestors, by Bing Xin, 1982)

This is a typical Chinese sentence. It is difficult to deal with if not seeing Zhang's translation first. In Chinese, the subject has switched from “我(wo)" (I) to “福建华侨(fu jian hua qiao)” (Fujianese expatriates). As the author “Bing Xin" was travelling with friends and relatives at home, so the translator added a subject "we" in translation, which is meant but not stated in the original text. The change of subjects necessitates division of sentences.

\subsection{Markers of Figures of Speech}

Figures of speech are considered an important means to present the writer or speaker's style. Frequently used figures of speech include simile, metaphor, analogy, hyperbole, metonymy, pun, irony, parallelism, etc. Bing Xin is good at applying figures of speech. It is often difficult to convey these rhetorical features, 
but we do need to find their appropriate counterparts in translation. For without these colorful rhetorical devices, cross-culture communication will definitely lose lots of shining points, the flavor of the original.

7) 特别是灯节, 那时我们家住在南后街, 那里是灯市的街, 元宵前后,

“花市灯如昼” , 灯影下人流潮涌, 那光明绚丽的情景就说不尽了。(来

自《我的父母之乡》, 冰心, 1982)

Particular mention, however, should be made of the Lantern Festival when Nanhoujie, the street known for its lantern fair and also the street where we lived, became as bright as broad daylight at night with myriads of lanterns and streams of spectators. The splendor and magnificence of the scene is beyond all description. (from "The Land of My Ancestors", by Bingxin, 1982)

The sentence “花市灯如昼(Huashi deng ru zhou)” (its lantern fair...with myriads of lanterns and streams of spectators) is quoted from the poem "Lantern Festival, to the tune of Sheng-cha-zi” (生查子・元夕(Sheng cha zi yuanxi)), written by Ouyang Xiu, a famous Chinese poet in Song dynasty. In this poem, he wrote “去年元夜时, 花市灯如昼 (qu nian yuan ye shi, hua shi deng ru zhou)” (In the Lantern Festival last year, lanterns were bright as if by day in the flower market) (by anonymous translator from internet), depicting a lively scene of the flower market, which was lighted up by the lanterns on the lantern fair. In this sentence with five characters, the poet managed to describe a beautiful scenery with succinct language, by applying a simile “灯如昼(deng ru zhou)” (bright as daytime), in which “如(ru)" has a similar meaning as the word "as" or "similar" in English. To achieve the equivalence in meaning and style, Zhang used a simile “as bright as broad daylight”. In the next sentence “灯影下人流潮涌(deng ying xia ren liu chao yong)" (...with myriads of lanterns and streams of spectators), the phase “人流潮涌(ren liu chao yong)" (streams of spectators) could be adapted from a Chinese metaphor “人潮(ren chao)", meaning “crowds of people are like tides". As people are there to enjoy the lanterns, Zhang used "spectators" instead of "people" to convey the hidden meaning. To be stylistically equivalent, he also chose a metaphor in English "streams of spectators", which perfectly matched with the Chinese, retaining the original meaning as well as the figures of speech.

\subsection{Textual Markers}

Textual markers refer to the organization mode of a text and also way of expression of a concept. They include how a writer develops his article and its textual patterns like cohesive and logic paragraphs or disordered and segmental speeches. All in all, textual markers help in analyzing the style of source language's textual structures effectively, be its simple and plain analytic style or complicated and elegant synthetic style. Hence, their translation would be conveyed appropriately in style. Bing Xin uses many parallel structures and a lot of symmetric and balanced sentences to create the rhythm and melody in her prose. When 
translating it into English, much attention should be paid to the logic relation among the sentences, paragraphs as well as the overall textual structure.

8）当由一个人物, 一桩事迹, 一幅画面而发生的真情实感, 向你袭来的 时候, 它就像一根扎到你心尖上的长针, 一阵卷到你面前的怒潮, 你只 能用最真切、最简练的文字, 才能描画出你心尖上的那一阵剧痛和你面 前的那一雬惊惶! (来自《话说短文》, 冰心, 1988)

When true emotions aroused by a person, an event or a scene come upon you like a pin pricking your heart or an angry tide surging threateningly before you, all you can do is use the most vivid and succinct language to describe the severe pain in your heart or the momentary feeling of panic caused by the angry tide. (From A Chat about Short Essays, Bing Xin, 1988)

This whole Chinese paragraph is composed of only one sentence, as can be seen from the exclamation mark "! ” at the end of the paragraph. The subject in original text has shifted from “真情实感(zhen qing shi gan)” (true emotions), to “它(ta)” (it), to “你(ni)” (you). When translating such long sentences with multiple clauses, one would likely to divide it into several sentences in order to be grammatically correct. However, that would mean a loss in style. As the long sentence in Chinese creates a closer connection in meaning among the clauses and it has a different rhythm compared with short ones. In this case, Zhang closely follows the original text in style by applying a long compound sentence in translation.

9) 寒暑表降到冰点下十八度的时候, 我们也是在廊下睡觉。每夜最熟识 的就是天上的星辰了。也不过只是点点闪柏的光明, 而相看惯了, 偶然 不见, 也有些想望与无聊。(73 words) (来自《雨雪时候的星辰》, 冰心) The thermometer had dropped to 18 degrees below zero, but we still chose to sleep in the porch as usual. In the evening, the most familiar sight to me would be stars in the sky. Though they were a mere sprinkle of twinkling dots, yet I had become so accustomed to them that their occasional absence would bring me loneliness and ennui. (62 words) (From Stars on a Snowy Night, Bing Xin)

Bing Xin's prose is famous for being succinct. In the translated version, there are sixty-two words, while the original one has seventy-three words. Both the translation and the original have only three sentences. Apart from that, Zhang applies some connectives to convey the original meaning, such as "but", “Though”, the English equivalent of “也(ye)” and “也不过(ye bu guo)” in Chinese. He also added several pronouns, like "to me", "they" and "I" to adapt to English grammatically, because these pronouns is only implied, but not stated in Chinese. The last sentence, “而相看惯了, 偶然不见, 也有些想望与无聊(er xiang kan guan le, ou ran bu jian, ye you xie xiang wang yu wu liao)" (yet I had become so accustomed to them that their occasional absence would bring me loneliness and ennui.), is terse and concise. If translated from the first person perspective, it would be tedious and lengthy. With a common English connective 
"so... that..." and it is shifted into a third person perspective, Zhang successfully recreates the style of Bing Xin's prose.

\section{Conclusions}

After careful and detailed discussion and analyses in this thesis, the paper concludes that retaining the style of the original text in prose translation is fully possible. The exploration is beneficial in these ways: Firstly, it combines both functional theory and stylistic marker theory in the analysis of style translation. With functional theory as a guide and stylistic markers as the criteria, the author believes this combination is practical for both translation and evaluation of style translation. "Form markers" provide a quantitative approach for the analysis of style, making the intangible style traceable. Secondly, Zhang Peiji's translation is as beautiful and elegant as the original prose. This study aims to boost the confidence of future translators and provide a feasible direction for style translation.

Indeed we have to admit style translation is a painstaking and profound task. This paper is only a tentative analysis on this topic with limited samples from Bing Xin's prose. The author believes more thorough and comprehensive research will be done in this field to shed a light on future translators and scholars.

\section{Conflicts of Interest}

The author declares no conflicts of interest.

\section{References}

[1] Hua, H.L. and Fang, W.J. (2020) Zhang Peiji's Style Reproduction from the Perspective of "Non-Form" Stylistic Markers. Cultural Journal, No. 4, 103-105.

[2] Zhang, L.M. (2020) Style Translation of English Prose from the Perspective of Functional Theory: A Case Study of Two Chinese Versions of First Snow. Overseas English, No. 16, 11-13.

[3] Yang, J. (2021) Style Translation of English Prose from the Perspective of Stylistic Markers Theory: A Case Study of Liu Bingshan's Chinese Version of a Dissertation upon Roast Pig. Journal of Henan Polytechnic University (Social Sciences), 22, 58-64.

[4] Nida, E.A. (1993) Language, Culture and Translating. Shanghai Foreign Language Education Press, Shanghai, 116.

[5] Liu, M.Q. (1985) Stylistics and Translation. China Translation and Publishing Corporation, Beijing, 484.

[6] Liu, M.Q. (1999) Modern Translation Theories. China Translation and Publishing Corporation, Beijing, 220-221.

[7] Merriam-Webster.com Dictionary, Merriam-Webster (2021) In Broad Daylight. https://www.merriam-webster.com/dictionary/in\%20broad\%20daylight 